\title{
A flow-microreactor approach to protecting-group- free synthesis using organolithium compounds
}

Heejin Kim', Aiichiro Nagaki \& Jun-ichi Yoshida ${ }^{1}$

Protecting-group-free synthesis has received significant recent research interest in the context of ideal synthesis and green sustainable chemistry. In general, organolithium species react with ketones very rapidly, and therefore ketone carbonyl groups should be protected before an organolithium reaction, if they are not involved in the desired transformation. If organolithium chemistry could be free from such a limitation, its power would be greatly enhanced. Here we show that a flow microreactor enables such protecting-group-free organolithium reactions by greatly reducing the residence time ( 0.003 s or less). Aryllithium species bearing ketone carbonyl groups are generated by iodine-lithium exchange reactions of the corresponding aryl iodides with mesityllithium and are reacted with various electrophiles using a flow-microreactor system. The present method has been successfully applied to the formal synthesis of Pauciflorol F. 
C ontinuous-flow microreactors based on microfluidics ${ }^{1-3}$ have been recognized as powerful tools for chemical synthesis, and studies on their characteristic features have uncovered a rich variety of synthetic applications in recent years ${ }^{4-25}$. Flowmicroreactor synthesis has also received much attention from the viewpoint of synthesis based on reaction integration ${ }^{26-30}$ and green sustainable synthesis ${ }^{31}$. Such successful applications speak well for the power of the flow-microreactor method in chemical synthesis. It is important to note that the reaction time in a flow microreactor is defined as the residence time between a reagent inlet and the quencher inlet, which can be controlled precisely and reduced to millisecond order by adjusting the length between these positions and the flow speed. On the basis of such a feature of flow microreactors, we have recently proposed the concept of flash chemistry $y^{32-35}$, which enables the use of short-lived highly reactive intermediates for synthesis. Such intermediates can be rapidly generated and transferred to another location in the flow system for use in subsequent reactions before they decompose. It is also noteworthy that the total production capacity over time of continuous-flow microreactors is much greater than may be imagined, although the reactor's capacity at any one time is small. Therefore, flow-microreactor synthesis can be used not only for laboratory-scale synthesis but also for the production of chemical substances on an industrial scale. In fact, there are flow microreactors that fit in the palm of the hand and can produce several tons of products per year ${ }^{36,37}$. Armed with an understanding of the essential principles, chemists are now in a position to enhance the capability of flow microreactions and to develop new synthetic transformations that are difficult to achieve by conventional batch reactions.

Organolithium species ${ }^{38,39}$ serve as powerful reagents in organic synthesis. However, they are not compatible with electrophilic functional groups such as ketone carbonyl groups. In fact, organolithium species react with ketones very rapidly. In some cases, organolithium species can be generated in the presence of ketones and quenched in situ by the ketone carbonyl group ${ }^{40}$. However, if a ketone carbonyl group is not involved in the desired transformation, it should be protected before an organolithium reaction, although ketone carbonyl groups survive in reactions of some less reactive organometallics ${ }^{41-43}$. Therefore, if organolithium reactions can be conducted without protecting the ketone carbonyl groups, the power of organolithium chemistry will be greatly enhanced.

Here we show that a flow microreactor enables protecting-groupfree organolithium reactions by greatly reducing the residence time ( $0.003 \mathrm{~s}$ or less); aryllithium species bearing ketone carbonyl groups are generated by iodine-lithium exchange reactions of the corresponding aryl iodides with mesityllithium and are reacted with various electrophiles using a flow-microreactor system by greatly reducing the residence time ( $0.003 \mathrm{~s}$ or less). We also show that the present method has been successfully applied to the formal synthesis of Pauciflorol F.

\section{Results}

Generation and reactions of acyl-substituted aryllithiums. We began our investigation by conducting the iodine-lithium exchange reaction of $o$ - and $p$-acyliodobenzenes followed by trapping with methanol using the flow-microreactor system, as shown in Figure 1 (see also Supplementary Fig. S1). Mesityllithium was first generated by a bromine-lithium exchange reaction of 2-bromo-1,3,5trimethylbenzene (mesityl bromide) and $n$-butyllithium at $0^{\circ} \mathrm{C}$,
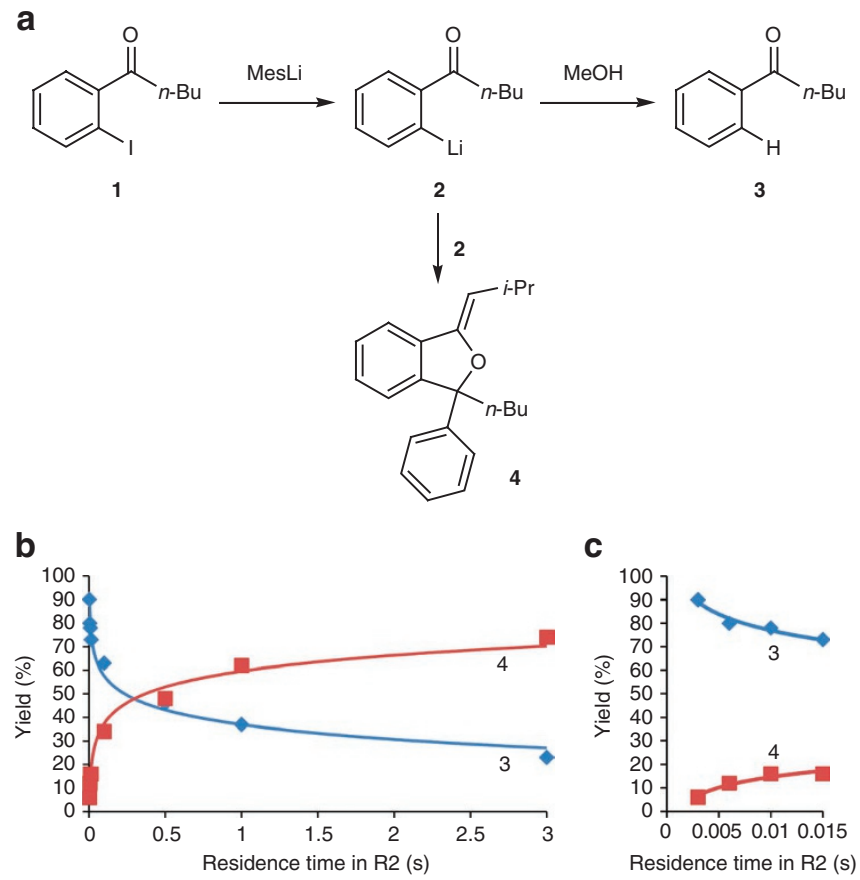

Figure $\mathbf{2}$ | The effect of residence time in $\mathbf{R} 2$ for the reaction of 0-pentanoyliodobenzene (1). (a) Reaction of $\mathbf{1}$ with MesLi to yield o-pentanoyl-substituted phenyllithium (2) followed by trapping with $\mathrm{MeOH}$ to produce protonated product $\mathbf{3}$. Undesired dimerization of $\mathbf{2}$ gave by-product $\mathbf{4}$. (b) Plots of the yield of $\mathbf{3}$ and $\mathbf{4}$ against the residence time in $\mathrm{R} 2(<3 \mathrm{~s})$. (c) Plots of the yield of $\mathbf{3}$ and $\mathbf{4}$ against the residence time in R2 $(<0.015 s)$.
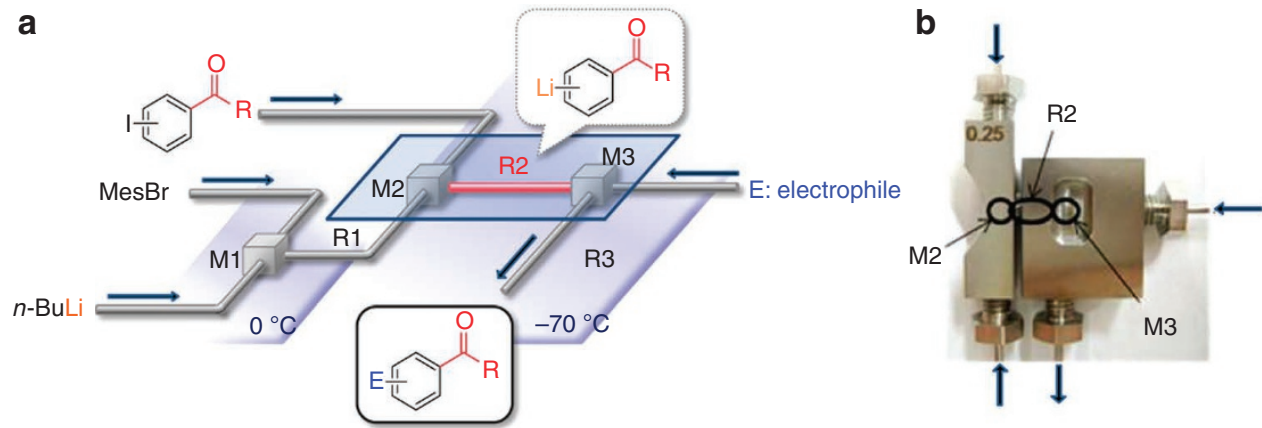

Figure 1 | A flow-microreactor system. (a) A schematic diagram of the system. 2-Bromo-1,3,5-trimethylbenzene (mesityl bromide, MesBr) was reacted with $n$-butyllithium using T-shaped micromixer $\mathrm{M} 1$ and microtube reactor $\mathrm{R} 1$ at $0^{\circ} \mathrm{C}$. The resulting mesityllithium solution was reacted with an acyliodobenzene in T-shaped micromixer $\mathrm{M} 2$ and microtube reactor $\mathrm{R} 2$ at $-70^{\circ} \mathrm{C}$. The resulting short-lived acylphenyllithium species was trapped with an electrophile using T-shaped micromixer $\mathrm{M} 3$ and microtube reactor $\mathrm{R} 3$ at $-70^{\circ} \mathrm{C}$. (b) An integrated device in which $\mathrm{M} 2$ (inner diameter: $250 \mu \mathrm{m}$ ), R2 (inner diameter: $250 \mu \mathrm{m}$, length: $1.0 \mathrm{~cm}$ ) and M3 (inner diameter: $250 \mu \mathrm{m}$ ) are combined. 


\section{Table 1 | Generation of acyl-substituted aryllithiums and reactions with electrophiles in a flow-microreactor system.}

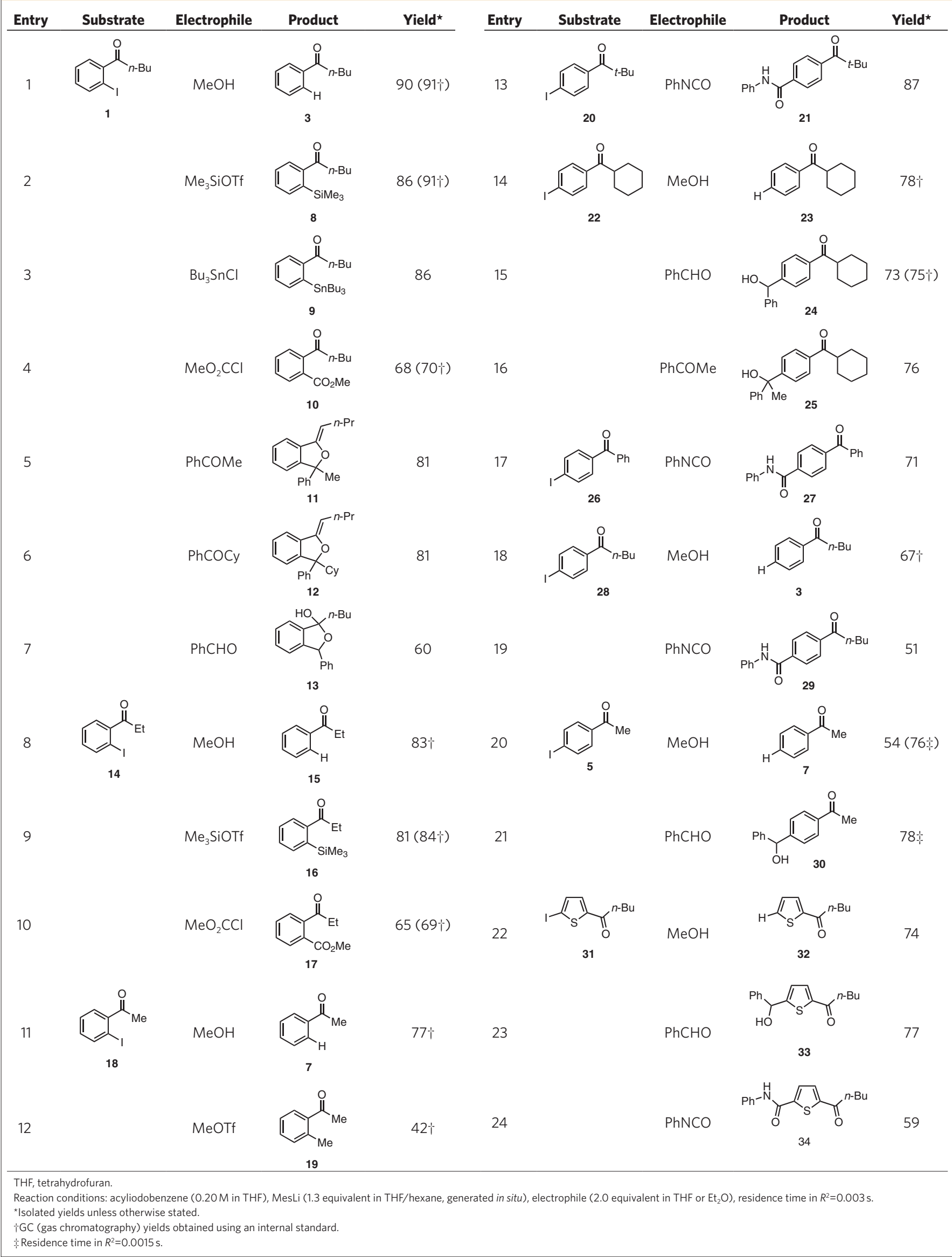


because preliminary studies showed that mesityllithium was the most effective compound for this purpose. The iodine-lithium exchange reaction of an acyliodobenzene using the resulting mesityllithium was conducted at $-70^{\circ} \mathrm{C}$. The short-lived acylphenyllithium species thus produced was trapped with methanol as an electrophile at $-70^{\circ} \mathrm{C}$ (Fig. 1a).

We focused on the generation of $o$-pentanoyl-substituted phenyllithium (2) generated from o-pentanoyliodobenzene (1). Methanol was used as a quenching electrophile (Fig. 2a). The reactions were carried out with variation in the residence time in R2, and the yield of the protonated product $\mathbf{3}$ was determined by gas chromatography (GC). The yield of $\mathbf{3}$ increased with a decrease in the residence time (Fig. 2b, see also Supplementary Table S1). However, acceptable yields were not obtained even at the minimum limit of the residence time of our current system $(0.01 \mathrm{~s})$, although this residence time was successful for the generation of alkoxycarbonyl $-{ }^{44}$, nitro- ${ }^{45}$ and cyano-substituted ${ }^{46}$ aryllithiums. Aryllithium 2 bearing a ketone carbonyl group decomposed very rapidly, the major by-product being dimeric compound 4 .

To avoid the decomposition of $\mathbf{2}$, we developed a new integrated device in which two T-shaped micromixers and one microreactor are combined (Fig. 1b). Although the Reynolds number is $\sim 10^{2}$, extremely fast mixing takes place at the T-shaped mixers, presumably because of engulfment flow ${ }^{47}$. Using this device, the residence time could be reduced to $0.003 \mathrm{~s}$, giving rise to a dramatic increase in the yield of product 3 (Fig. 2c). The result clearly indicates that a ketone carbonyl group could survive a residence time of a few milliseconds.

At a residence time of $0.003 \mathrm{~s}$, generation of various $o$-acylsubstituted aryllithium species followed by reactions with various electrophiles including $\mathrm{Me}_{3} \mathrm{SiOTf}, \mathrm{Bu}_{3} \mathrm{SnCl}$ and $\mathrm{ClCO}_{2} \mathrm{Me}$ were successfully conducted, and the corresponding products bearing unchanged ketone carbonyl groups were obtained in good yields and productivity $\left(0.25-0.54 \mathrm{mmol} \mathrm{min}^{-1}\right.$; Table 1 , entries $\left.1-12\right)$. It is interesting that some ketones could be used as electrophiles, although they should be more reactive than the carbonyl group of the acylphenyllithium species (entries 5 and 6).

The generation and reaction of $p$-acyl-substituted phenyllithiums led to slightly lower yields of the products (entries 13-21) compared with the corresponding $o$-acyl-substituted phenyllithiums, presumably because of the lack of coordination of the carbonyl group to lithium. In particular, in the case of $p$-acetylphenyllithium (6) generated from $p$-acetyliodobenzene (5), the protonated product 7 was obtained only in moderate yield (54\%, entry 20 ). This problem could be solved by further reducing the residence time in R2, which was achieved by increasing the flow rate using a high-pressure syringe pump. As shown in Figure 3, the yield of 7 increased with a decrease in the residence time, and an acceptable yield (76\%) was obtained at a residence time of $0.0015 \mathrm{~s}$ (see also Supplementary Table S2). This residence time also allowed efficient reaction with $\mathrm{PhCHO}$ to produce the corresponding product in $78 \%$ yield (entry 21 ). Heteroaromatic iodides such as 1-(5-iodothiophen-2-yl)pentan-1-one $\mathbf{3 1}$ could also be lithiated and the resulting organolithium compounds were effectively trapped with electrophiles without affecting the ketone carbonyl group (entries 22-24).

Application to formal synthesis of Pauciflorol F. Using the present method, Pauciflorol $\mathrm{F}^{48}$, a natural product isolated from stem bark, which has recently been synthesized by Snyder's group ${ }^{49,50}$ and Sarpong's group ${ }^{51}$, was synthesized. The starting material 35 was prepared from commercially available 3,5-dimethoxyphenylmagnesium chloride in two steps (67\% yield; Fig. 4). The iodine-lithium exchange reaction of 35 followed by reaction with 3,5-dimethoxybenzaldehyde was conducted using a flow-microreactor system consisting of the integrated device (residence time in R2: $0.003 \mathrm{~s}$ ) to produce 36 (ref. 49) in 81\% isolated yield. Presumably, dehydration
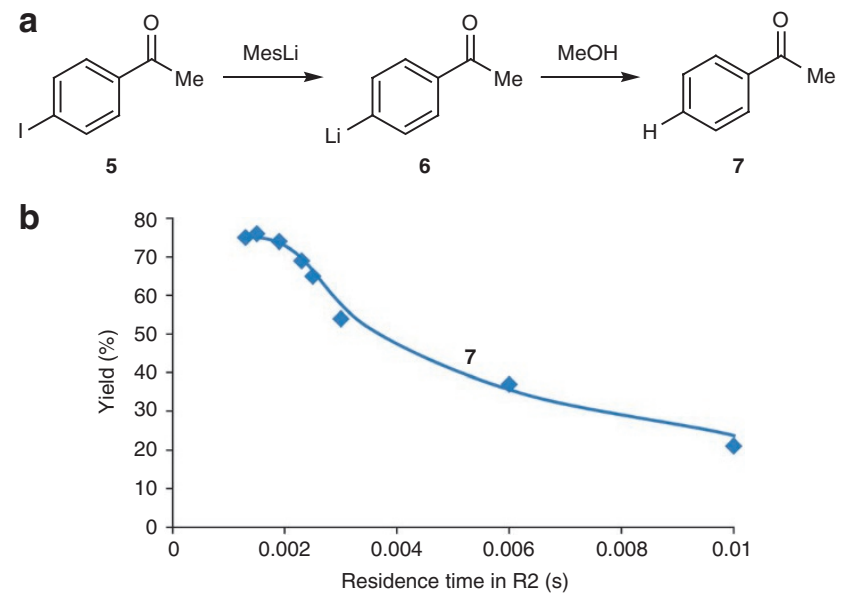

Figure 3 | The effect of residence time in $\mathbf{R 2}$ for the reaction of p-acetyliodobenzene (5). (a) Reaction of $\mathbf{5}$ with MesLi to yield p-acetylphenyllithium (6) followed by trapping with $\mathrm{MeOH}$ to produce protonated product 7. (b) Dependence of the yield of $\mathbf{7}$ on the residence time in R2 (<0.01s).

took place upon acidic work-up. Treatment of $\mathbf{3 6}$ with $\mathrm{HCl} / i-\mathrm{PrOH}$ in the presence of $\mathrm{O}_{2}$ in a batch reactor gave 37 in $75 \%$ yield, which can be converted to Pauciflorol F by one-pot hydrogenation and epimerization $(87 \%)^{51}$ followed by deprotection $(86 \%)^{49,50}$.

\section{Discussion}

Recently, the construction of complicated organic molecules without using protecting groups (protecting-group-free synthesis) ${ }^{52,53}$, especially from the viewpoints of atom economy ${ }^{54}$, step economy ${ }^{55}$ and redox economy ${ }^{56}$, has received significant research interest in the context of ideal synthesis ${ }^{57}$ and green sustainable chemistry ${ }^{58}$. Generally, skeleton-building steps are the most difficult with respect to avoiding usage of protecting groups because such steps often use strongly basic nucleophilic reagents. Among such reagents, organolithium reagents are the most reactive. However, a major drawback of organolithium species is that they are too reactive and rapidly react with electrophilic functional groups such as ketone carbonyl groups, which are often present in the desired target organic structures. Therefore, organic textbooks say that a ketone carbonyl group should be protected before an organolithium reaction if it is not involved in the desired transformation. However, we have demonstrated here that aryl- and heteroaryllithium species bearing ketone carbonyl groups can be generated and used for desired reactions by greatly reducing the residence time in a flow microreactor to a few milliseconds. Within such an extremely short residence time, the organolithium intermediates can survive and be used for reactions with various external electrophiles without affecting the ketone carbonyl group in the same molecule.

The formal synthesis of Pauciflorol $\mathrm{F}$ achieved in this study (Fig. 4) demonstrates the potential of the present flow-microreactor approach. Although the synthesis by Snyder's group based on a biomimetic strategy and the synthesis by Sarpong's group based on a Larock annulations strategy are elegant and concise, our synthesis is comparable from the viewpoints of atom economy and step economy. Because the productivity of the present method is relatively high ( $1.06 \mathrm{~g}$ for $5 \mathrm{~min}$ operation), it is hoped that the flow-microreactor method will provide a green and sustainable way of producing useful compounds such as Pauciflorol F in the pharmaceutical and fine chemicals industries in the future.

The present approach based on control of the residence time in a flow microreactor serves as a powerful method for protecting-group-free synthesis using organolithium reagents, which 

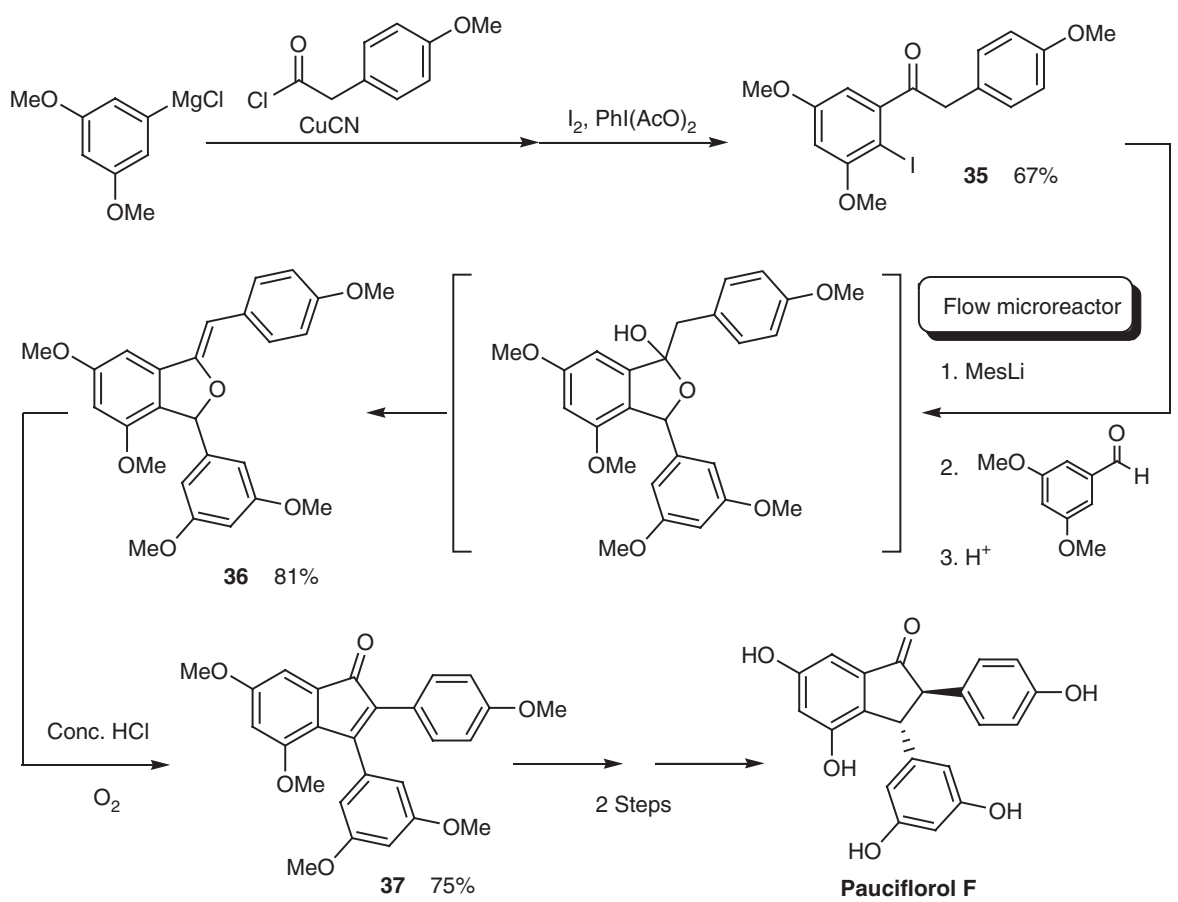

Figure 4 | Formal total synthesis of Pauciflorol F. The flow-microreactor reaction of iodoketone $\mathbf{3 5}$ gave compound $\mathbf{3 6}$ ( $81 \%$ yield, $1.06 \mathrm{~g}$ for 5 min operation), which can be converted to Pauciflorol $\mathrm{F}$ according to the literature procedure.

is complementary to other approaches using less reactive and more chemoselective reagents. Although the flow-microreactor approach is still in its infancy, it is clearly capable, powerful and useful from both scientific and practical viewpoints. Currently, work to expand further the capability of flow-microreactor synthesis is in progress.

\section{Methods}

General procedure. A flow-microreactor system consisting of three T-shaped micromixers (M1, M2 and M3) and three microtube reactors (R1, R2 and R3) was used. A solution of mesityl bromide in tetrahydrofuran (THF; $0.18 \mathrm{M}$, flow rate: $\left.5.0 \mathrm{ml} \mathrm{min}^{-1}\right)$ and a solution of $n$-BuLi in hexane $\left(0.43 \mathrm{M}\right.$, flow rate: $\left.1.8 \mathrm{ml} \mathrm{min}^{-1}\right)$ were introduced to M1 (inner diameter: $250 \mu \mathrm{m}$ ). The resulting solution was passed through R1 and was mixed with a solution of acyliodobenzene in THF $(0.20 \mathrm{M}$, flow rate: $3.0 \mathrm{ml} \mathrm{min}^{-1}$ ) in M2 (inner diameter: $250 \mu \mathrm{m}$ ). The resulting solution was passed through R2 and then mixed with a solution of an electrophile $(0.60 \mathrm{M}$, flow rate: $2.0 \mathrm{ml} \mathrm{min}^{-1}$ ) in M3 (inner diameter: $250 \mu \mathrm{m}$ ). The resulting solution was passed through R3. After a steady state was reached, the product solution was collected for $30 \mathrm{~s}$ while being quenched with aqueous sat. $\mathrm{NH}_{4} \mathrm{Cl}$ solution $(2 \mathrm{ml})$. The aqueous layer was extracted three times with ether $(25 \mathrm{ml})$. The combined organic extracts were dried over $\mathrm{Na}_{2} \mathrm{SO}_{4}$ and concentrated. The crude product was purified by chromatography. Details of the synthesis, purification and characterization are given in Supplementary Figures S2-S25.

Formal total synthesis of Pauciflorol F. In all, $1 \mathrm{M} \mathrm{CuCN} \cdot 2 \mathrm{LiCl}$ THF solution $(44 \mathrm{ml}, 44.0 \mathrm{mmol}$ ) was added dropwise to a solution of 3,5-dimethoxyphenylmagnesium chloride $(0.5 \mathrm{M}$ in THF, $80 \mathrm{ml}, 40.0 \mathrm{mmol})$ at $-25^{\circ} \mathrm{C}$ for $10 \mathrm{~min}$. After being stirred for $40 \mathrm{~min}$ at $-20^{\circ} \mathrm{C}$, 4-methoxyphenylacetyl chloride $(9.793 \mathrm{~g}$, $53.0 \mathrm{mmol}$ ) was added dropwise for $5 \mathrm{~min}$. The solution was slowly warmed to $-10^{\circ} \mathrm{C}$ for $1 \mathrm{~h}$, and the reaction was quenched by slow addition of sat. $\mathrm{NH}_{4} \mathrm{Cl}$ solution $(120 \mathrm{ml})$. The organic layer was separated and the aqueous layer was extracted with $\mathrm{Et}_{2} \mathrm{O}(150 \mathrm{ml} \times 3)$. The combined organic layers were dried over $\mathrm{Na}_{2} \mathrm{SO}_{4}$ and concentrated. The crude product was purified by column chromatography $\left(\mathrm{CHCl}_{3}\right)$ and washed with cold hexane to obtain 1-(3,5-dimethoxyphenyl)-2(4-methoxyphenyl)ethanone in 91\% yield (Supplementary Fig. S26).

Iodobenzene diacetate $(242.0 \mathrm{mg}, 0.75 \mathrm{mmol})$ was added to a solution of 1-(3,5-dimethoxyphenyl)-2-(4-methoxyphenyl)ethanone ( $146.8 \mathrm{mg}, 0.51 \mathrm{mmol})$ and iodine $(70.9 \mathrm{mg}, 0.28 \mathrm{mmol})$ in $\mathrm{CH}_{2} \mathrm{Cl}_{2}(4 \mathrm{ml})$ at $0{ }^{\circ} \mathrm{C}$. After being stirred at $0^{\circ} \mathrm{C}$ for $10 \mathrm{~h}$, the solution was slowly warmed to ambient temperature. After being stirred for $14 \mathrm{~h}$, the reaction was quenched by addition of half-saturated $\mathrm{Na}_{2} \mathrm{~S}_{2} \mathrm{O}_{3}$ solution $(10 \mathrm{ml})$. The organic layer was separated and the aqueous layer was extracted with $\mathrm{CH}_{2} \mathrm{Cl}_{2}(25 \mathrm{ml} \times 3)$. The combined organic layers were dried over $\mathrm{Na}_{2} \mathrm{SO}_{4}$ and concentrated. The crude product was purified by column chroma- tography (hexane/AcOEt = 4:1) to obtain 1-(2-iodo-3,5-dimethoxyphenyl)-2-(4methoxyphenyl)ethanone (35) in 74\% yield (Supplementary Fig. S27).

The flow-microreactor system shown in Figure la containing the integrated device (Fig. 1b) was used. A solution of 2-bromomesitylene (0.18 M in THF, $\left.5.0 \mathrm{ml} \mathrm{min}^{-1}\right)$ and a solution of $n$-BuLi $\left(0.43 \mathrm{M}\right.$ in hexane, $\left.1.8 \mathrm{ml} \mathrm{min}^{-1}\right)$ were introduced to M1 (inner diameter: $250 \mu \mathrm{m}$ ) by syringe pumps. The resulting solution was passed through R1 (inner diameter: $1,000 \mu \mathrm{m}$, length: $210 \mathrm{~cm}(100 \mathrm{~cm}$ at $0{ }^{\circ} \mathrm{C}, 10 \mathrm{~cm}$ at ambient temperature and $100 \mathrm{~cm}$ at $\left.-70^{\circ} \mathrm{C}\right)$ ) and was subsequently mixed with a solution of acyliodobenzene $35\left(0.20 \mathrm{M}\right.$ in THF, $\left.3.0 \mathrm{ml} \mathrm{min}^{-1}\right)$ at M2 (inner diameter: $250 \mu \mathrm{m}$ ). The resulting solution was passed through R2 (inner diameter: $250 \mu \mathrm{m}$, length: $1.0 \mathrm{~cm})$ and 3,5-dimethoxybenzaldehyde $(0.60 \mathrm{M}$ in THF, $2.0 \mathrm{ml} \mathrm{min}^{-1}$ ) was added at M3 (inner diameter: $250 \mu \mathrm{m}$ ). The resulting solution was passed through R3 (inner diameter: $1,000 \mu \mathrm{m}$, length: $50 \mathrm{~cm}$ ). After a steady state was reached, the product solution was collected for $5 \mathrm{~min}$ while being quenched with $\mathrm{H}_{2} \mathrm{O}(20 \mathrm{ml})$. After $1 \mathrm{M} \mathrm{HCl}$ solution $(80 \mathrm{ml})$ was added, the organic layer was separated and the remaining aqueous layer was extracted with $\mathrm{Et}_{2} \mathrm{O}(100 \mathrm{ml} \times 3)$. The combined organic layers were dried over $\mathrm{Na}_{2} \mathrm{SO}_{4}$ and concentrated. The crude product was purified by column chromatography (hexane/AcOEt $=2: 1$ ) to obtain 3-(3,5-dimethoxyphenyl)-4,6-dimethoxy-1-(4-methoxybenzylidene)-1,3-dihydroisobenzofuran (36) in 81\% yield (1.058 g; Supplementary Fig. S28).

Aqueous conc. $\mathrm{HCl}$ solution $(4 \mathrm{ml})$ was added dropwise for $30 \mathrm{~min}$ to a solution of $36(44.0 \mathrm{mg}, 0.101 \mathrm{mmol})$ in $i-\mathrm{PrOH}(20 \mathrm{ml})$ at $25^{\circ} \mathrm{C}$. After being stirred for $12 \mathrm{~h}$ under an oxygen atmosphere, the reaction was quenched by slow addition of aqueous sat. $\mathrm{NaHCO}_{3}$ solution $(60 \mathrm{ml})$ and water $(40 \mathrm{ml})$ at $0^{\circ} \mathrm{C}$. The organic layers were extracted with AcOEt $(40 \mathrm{ml} \times 3)$ and washed with brine $(40 \mathrm{ml})$. The combined organic layers were dried over $\mathrm{Na}_{2} \mathrm{SO}_{4}$ and concentrated. The crude product was purified by column chromatography (hexane/AcOEt $=3: 1$ ) to obtain 3-(3,5-dimethoxyphenyl)-4,6-dimethoxy-2-(4-methoxyphenyl)-1H-inden-1-one (37) in 75\% yield (Supplementary Fig. S29), which can be converted to Pauciflorol $\mathrm{F}$ by one-pot hydrogenation and epimerization followed by deprotonation.

\section{References}

1. Whitesides, G. The origins and the future of microfluidics. Nature 442, 368-373 (2006)

2. deMello, A. J. Control and detection of chemical reactions in microfluidic systems. Nature 442, 394-402 (2006).

3. Song, H., Chen, D. L. \& Ismagilov, R. F. Reactions in droplets in microfluidic channels. Angew. Chem. Int. Ed. 45, 7336-7356 (2006).

4. Ley, S. V. The changing face of organic synthesis. Tetrahedron $\mathbf{6 6 , 6 2 7 0 - 6 2 9 2}$ (2010).

5. Marrea, S. \& Jensen, K. F. Synthesis of micro and nanostructures in microfluidic systems. Chem. Soc. Rev. 39, 1183-1202 (2010).

6. Frost, C. G. \& Mutton, L. Heterogeneous catalytic synthesis using microreactor technology. Green Chem. 12, 1687-1703 (2010). 
7. Hessel, V., Renken, A., Schouten, J. C. \& Yoshida, J. Micro Process Engineering: A Comrehensive Handbook Vol. 1-3 (Wiley-VCH, 2009).

8. Lin, W., Wang, Y., Wang, S. \& Tseng, H. Integrated microfluidic reactors. Nano Today 4, 470-481 (2009).

9. Geyer, K., Gustafsson, T. \& Seeberger, P. H. Developing continuous-flow microreactors as tools for synthetic chemists. Synlett 2382-2391 (2009).

10. Hartman, R. L. \& Jensen, K. F. Microchemical systems for continuous-flow synthesis. Lab Chip 9, 2495-2507 (2009).

11. Ziogas, A. et al. Electrochemical microstructured reactors: design and application in organic synthesis. J. Appl. Electrochem. 39, 2297-2313 (2009).

12. Fukuyama, T., Rahman, Md.T., Sato, M. \& Ryu, I. Adventures in inner space: microflow systems for practical organic. Synlett 151-163 (2008).

13. Kockmann, N., Gottsponer, M., Zimmermann, B. \& Roberge, D. M. Enabling continuous-flow chemistry in microstructured devices for pharmaceutical and fine-chemical production. Chem. Eur. J. 14, 7470-7477 (2008).

14. Bentio-López, F., Egberink, R. J. M., Reinhoudt, D. N. \& Verboom, W. High pressure in organic chemistry on the way to miniaturization. Tetrahedron 64 , 10023-10040 (2008).

15. Wilms, D., Klos, J. \& Frey, H. Microstructured reactors for polymer synthesis: a renaissance of continuous flow processes for tailor-made macromolecules? Macromol. Chem. Phys. 209, 343-356 (2008).

16. Ahmed-Omer, B., Brandt, J. C. \& Wirth, T. Advanced organic synthesis using microreactor technology. Org. Biomol. Chem. 5, 733-740 (2007).

17. Watts, P. \& Wiles, C. Recent advances in synthetic micro reaction technology. Chem. Commun. 443-467 (2007)

18. Kobayashi, J., Mori, Y. \& Kobayashi, S. Multiphase organic synthesis in microchannel reactors. Chem. Asian J. 1, 22-35 (2006).

19. Geyer, K., Codée, J. D. C. \& Seeberger, P. H. Microreactors as tools for synthetic chemists-the chemists round-bottomed flask of the 21st century? Chem. Eur. J. 12, 8434-8442 (2006).

20. Doku, G. N., Verboom, W., Reinhoudt, D. N. \& van den Berg, A. On-microchip ultiphase chemistry-a review of microreactor design principles and reagent contacting modes. Tetrahedron 61, 2733-2742 (2005).

21. Watts, P. \& Haswell, S. J. The application of micro reactors for organic synthesis. Chem. Soc. Rev. 34, 235-246 (2005).

22. Kiwi-Minsker, L. \& Renken, A. Microstructured reactors for catalytic reactions. Catalysis Today 110, 2-14 (2005)

23. Kikutani, Y. \& Kitamori, T. Micro-flow reaction systems for combinatorial syntheses. Macromol. Rapid Commun. 25, 158-168 (2004)

24. Jähnisch, K., Hessel, V., Löwe, H. \& Baerns, M. Chemistry in microstructured reactors. Angew. Chem. Int. Ed. 43, 406-446 (2004)

25. Schwalbe, T., Autze, V., Hohmann, M. \& Stirner, W. Novel innovation systems for a cellular approach to continuous process chemistry from discovery to market. Org. Process Res. Dev. 8, 440-454 (2004).

26. Suga, S., Yamada, D. \& Yoshida, J. Cationic three-component coupling involving an optically active enamine derivative from time integration to space integration of reactions. Chem. Lett. 39, 404-406 (2010).

27. Webb, D. \& Jamison, T. F. Continuous flow multi-step organic synthesis. Chem. Sci. 1, 675-680 (2010).

28. Sahoo, H. R., Kralj, J. G. \& Jensen, K. F. Multistep continuous-flow microchemical synthesis involving multiple reactions and separations. Angew. Chem. Int. Ed. 46, 5704-5708 (2007).

29. Kirschning, A., Solodenko, W. \& Mennecke, K. Combining enabling techniques in organic synthesis: continuous flow processes with heterogenized catalysts. Chem. Eur. J. 12, 5972-5990 (2006).

30. Lee, C.- C. et al. Multistep synthesis of a radiolabeled imaging probe using integrated microfluidics. Science 310, 1793-1796 (2005).

31. Mason, B. P., Prince, K. E., Steinbacher, J. L., Bogdan, A. R. \& McQuade, D. T. Greener approaches to organic synthesis using microreactor technology. Chem. Rev. 107, 2300-2318 (2007).

32. Yoshida, J. Flash chemistry: flow microreactor synthesis based on highresolution reaction time control. Chem. Record 10, 332-341 (2010).

33. Yoshida, J. Flash Chemistry Fast Organic Synthesis in Microsystems (Wiley, 2008).

34. Yoshida, J., Nagaki, A. \& Yamada, T. Flash chemistry: fast chemical synthesis by using microreactors. Chem. Eur. J. 14, 7450-7459 (2008).

35. Yoshida, J. Flash chemistry using electrochemical method and microsystems. Chem. Commun. 4509-4516 (2005).

36. Wakami, H. \& Yoshida, J. Grignard exchange reaction using a microflow system: from bench to pilot plan. Org. Process Res. Dev. 9, 787-791 (2005).

37. Roberge, D. M., Zimmermann, B., Rainone, F., Gottsponer, M., Eyholzer, M. \& Kochmann, N. Microreactor technology and continuous processes in the fine chemical and pharmaceutical industry: is the revoluiton underway? Org. Process Res. Dev. 12, 905-910 (2008)
38. Schlosser, M. The organometallic approach to molecular diversityhalogens as helpers. Eur. J. Org. Chem. 21, 3975-3984 (2001).

39. Whisler, M. C., MacNeil, S., Snieckus, V. \& Beak, P. Beyond thermodynamic acidity: a perspective on the complex-induced proximity effect (CIPE) in deprotonation reactions. Angew. Chem. Int. Ed. 43, 2206-2225 (2004).

40. Rutherford, J. L., Ferry, G., Hawkins, J. M. \& Lyme, O. Preparation of novel substituted haloarene compounds US 7,273,938 B2 (2007).

41. Yang, X. \& Knochel, P. Selective functionalization of imidazoles via an iodine-copper exchange reaction. Chem. Commun. 2170-2172 (2006)

42. Yang, X., Rotter, T., Piazza, C. \& Knochel, P. Successive iodine-magnesium or -copper exchange reactions for the selective functionalization of polyhalogenated aromatics. Org. Lett. 5, 1229-1231 (2003).

43. Kneisel, F. F. \& Knochel, P. Synthesis and reactivity of aryl- and heteroarylmagnesium reagents bearing keto groups. Synlett 1799-1802 (2002).

44. Nagaki, A., Kim, H. \& Yoshida, J. Aryllithium compounds bearing alkoxycarbonyl groups: generation and reactions using a microflow system. Angew. Chem. Int. Ed. 47, 7833-7836 (2008).

45. Nagaki, A., Kim, H. \& Yoshida, J. Nitro-substituted aryl lithium compounds in microreactor synthesis: switch between kinetic and thermodynamic control. Angew. Chem. Int. Ed. 48, 8063-8065 (2009).

46. Nagaki, A., Kim, H., Usutani, H., Matsuo, C. \& Yoshida, J. Generation and reaction of cyano-substituted aryllithium compounds using microreactors. Org. Biomol. Chem. 8, 1212-1217 (2010).

47. Soleymani, A., Yousefi, H. \& Turunen, I. Dimensionless number for identification of flow patterns inside a T-micromixer. Chem. Eng. Sci. 63, 5291-5297 (2008).

48. Ito, T. et al. Three new resveratrol oligomers from the stem bark of Vatica pauciflora. J. Nat. Prod. 67, 932-937 (2004).

49. Snyder, S. A., Breazzano, S. P., Ross, A. G., Lin, Y. \& Zografos, A. L. Total synthesis of diverse carbogenic complexity within the resveratrol class from a common building block. J. Am. Chem. Soc. 131, 1753-1765 (2009).

50. Snyder, S. A., Zografox, A. L. \& Lin, Y. Total synthesis of resveratrol-based natural products: a chemoselective solution. Angew. Chem. Int. Ed. 46, 8186-8191 (2007).

51. Jeffrey, J. L. \& Sarpong, R. Concise synthesis of Pauciflorol F using a Larock annulation. Org. Lett. 11, 5450-5453 (2009)

52. Young, I. S. \& Baran, P. S. Protecting-group-free synthesis as an opportunity for invention. Nat. Chem. 1, 193-204 (2009).

53. Hoffmann, R. W. Protecting-group-free synthesis. Synthesis 3531-3541 (2006)

54. Trost, B. M. The atom economy-a search for synthetic efficiency. Science 254, 1471-1477 (1991).

55. Wender, P. A., Verma, V. A., Paxton, T. J. \& Pillow, T. H. Function-oriented synthesis, step economy, and drug design. Acc. Chem. Res. 41, 40-49 (2008).

56. Burns, N. Z., Baran, P. S. \& Hoffmann, R. W. Redox economy in organic synthesis. Angew. Chem. Int. Ed. 48, 2854-2867 (2009).

57. Hendrickson, J. B. Systematic synthesis design. IV. Numerical codification of construction reactions. J. Am. Chem. Soc. 97, 5784-5800 (1975).

58. Poliakoff, M., Fitzpatrick, J. K., Farren, T. R. \& Anastas, P. T. Green chemistry: science and politics of change. Science 297, 807-809 (2002).

\section{Acknowledgments}

We thank the Grant-in-Aid for Scientific Research on Innovative Areas 2105 Organic Synthesis Based on Reaction Integration Development of New Methods and Creation of New Substances from the Ministry of Education, Culture, Sports, Science \& Technology, Japan for financial support. H.K. acknowledges JSPS for financial support.

\section{Author contributions}

H.K. assisted in conducting and analysing the chemical experiments. A.N. conceived and designed the experiments. J.-i.Y. designed, directed the project and wrote the manuscript with contributions from H.K. and A.N. All authors contributed to discussions.

\section{Additional information}

Supplementary Information accompanies this paper at http://www.nature.com/ naturecommunications

Competing financial interests: The authors declare no competing financial interests.

Reprints and permission information is available online at http://npg.nature.com/ reprintsandpermissions/

How to cite this article: Yoshida, J.-i. et al. A flow-microreactor approach to protectinggroup-free synthesis using organolithium compounds. Nat. Commun. 2:264 doi: $10.1038 /$ ncomms $1264(2011)$ 